\title{
Feeding activity and diet composition of round goby (Neogobius melanostomus) in the coastal waters of SE Baltic Sea
}

\author{
Artūras Skabeikis ${ }^{1,2}$, Jūratè Lesutienè ${ }^{1}$
}

${ }^{1}$ Marine Science and Technology Center, Klaipéda University, Herkaus Manto 84, LT-92294, Klaipéda, Lithuania

${ }^{2}$ Lithuanian Sea Museum, Smiltynès 3, LT-93100, Klaipéda, Lithuania
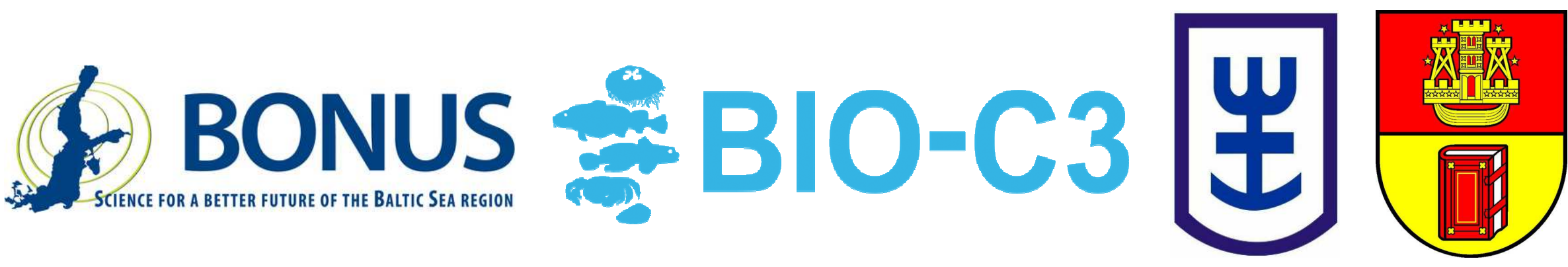


\section{Introduction}

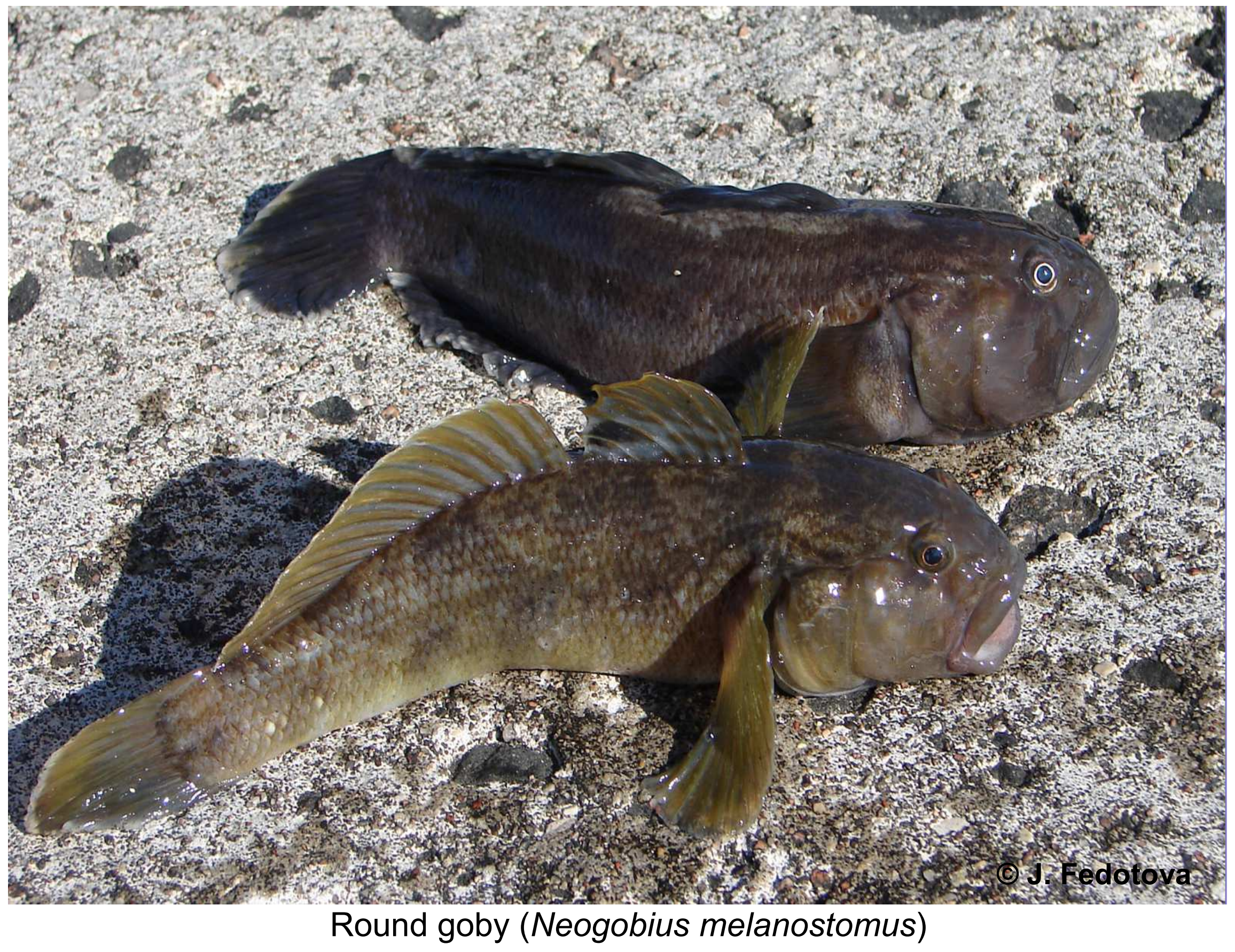




\section{Dispersion pattern of round goby in the Baltic Sea}

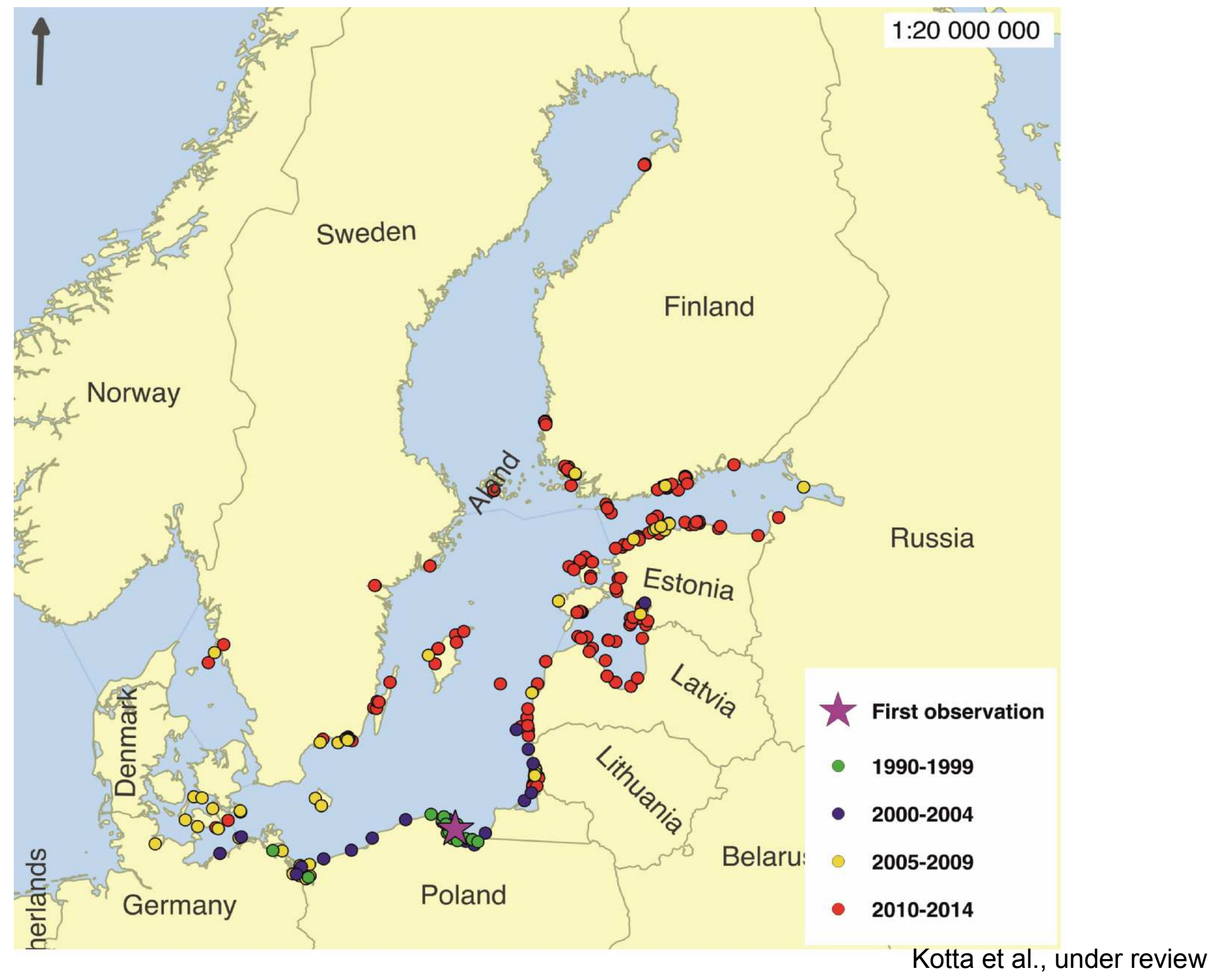




\section{Abundance dynamics of round goby in the Lithuanian coastal waters of the Baltic Sea}

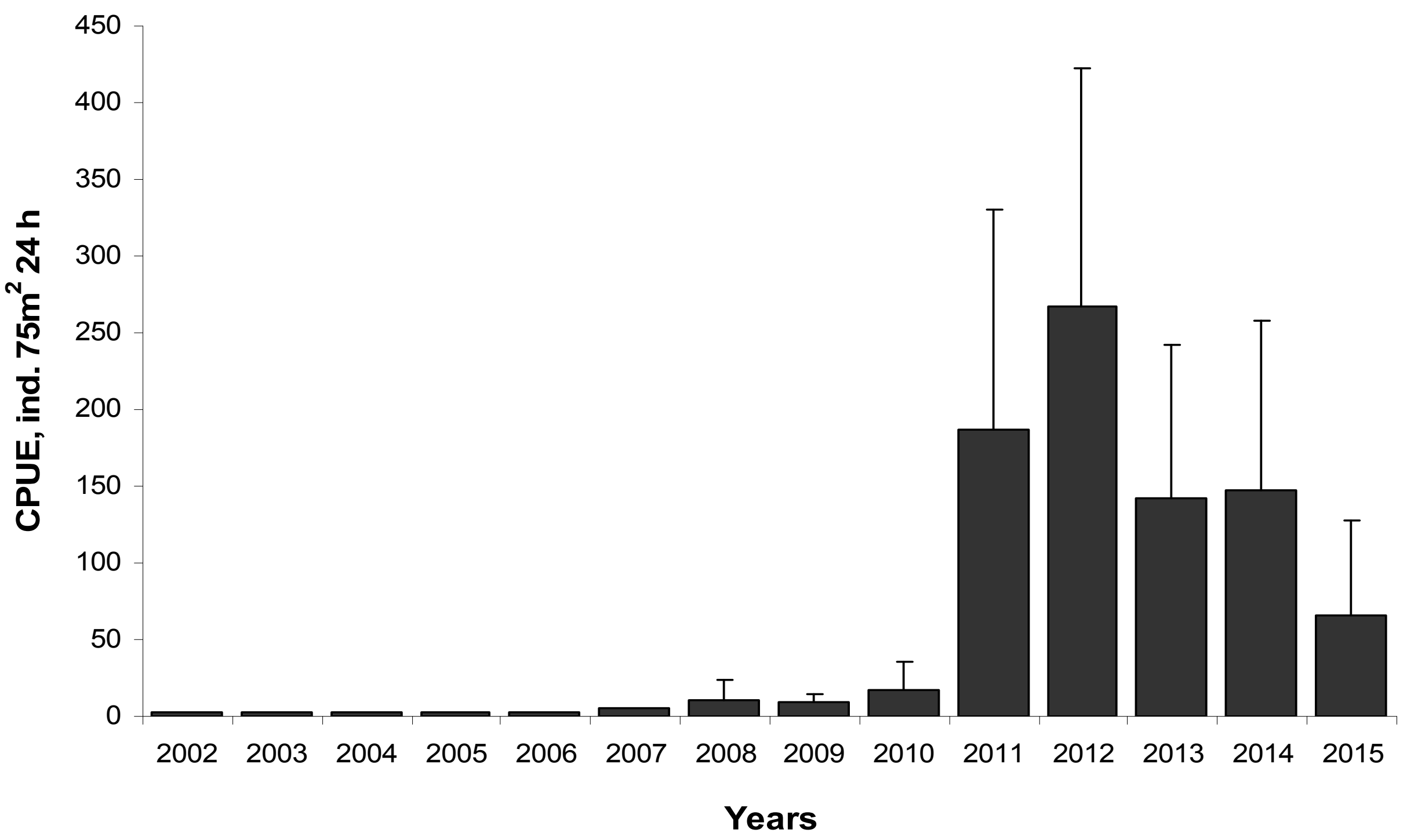

Monitoring data of the Fisheries Service under the Ministry of Agriculture of the Republic of Lithuania 


\section{Role of round goby in the food web of the Baltic Sea coastal ecosystem}

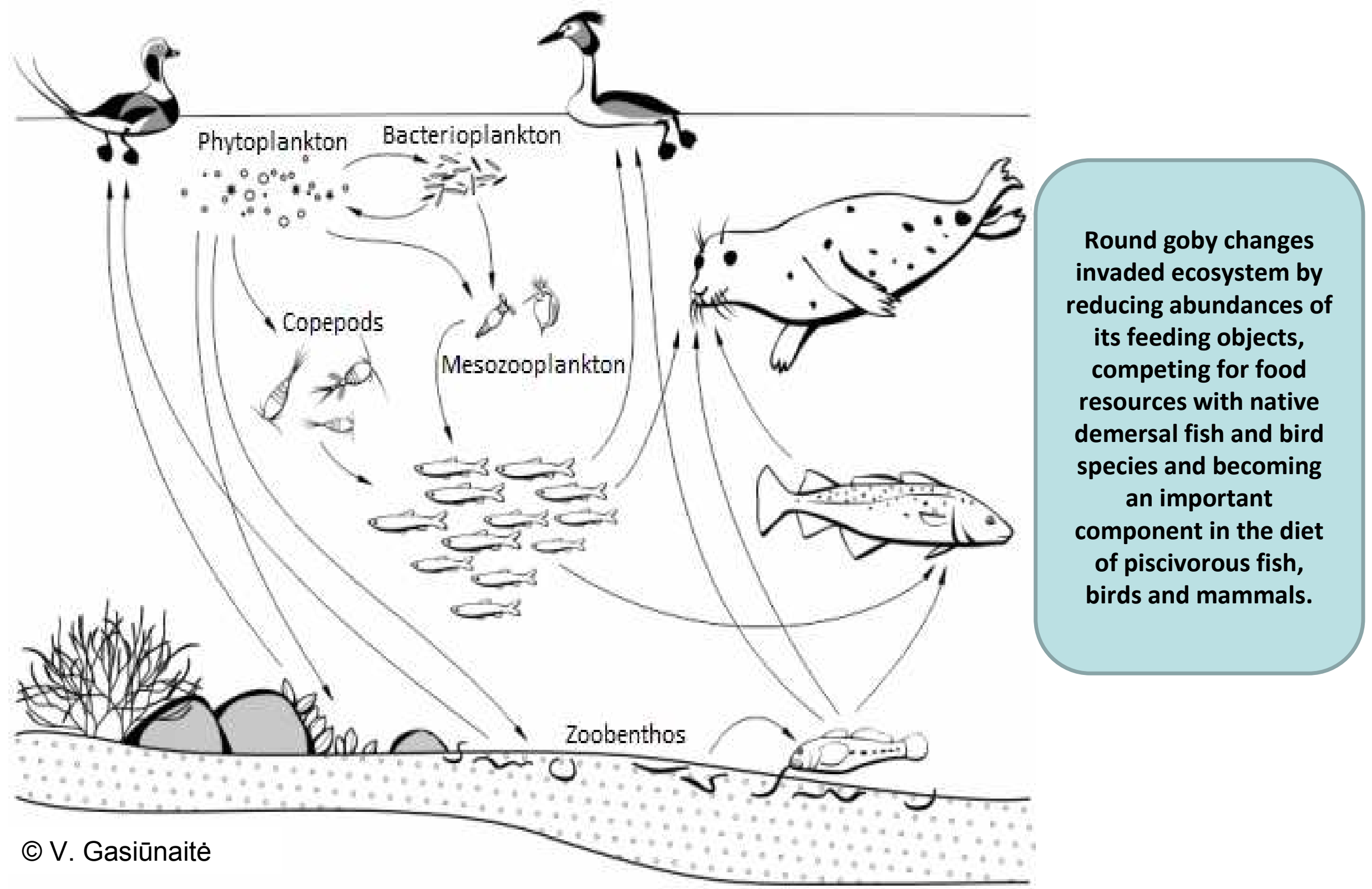




\section{Study site and sampling}
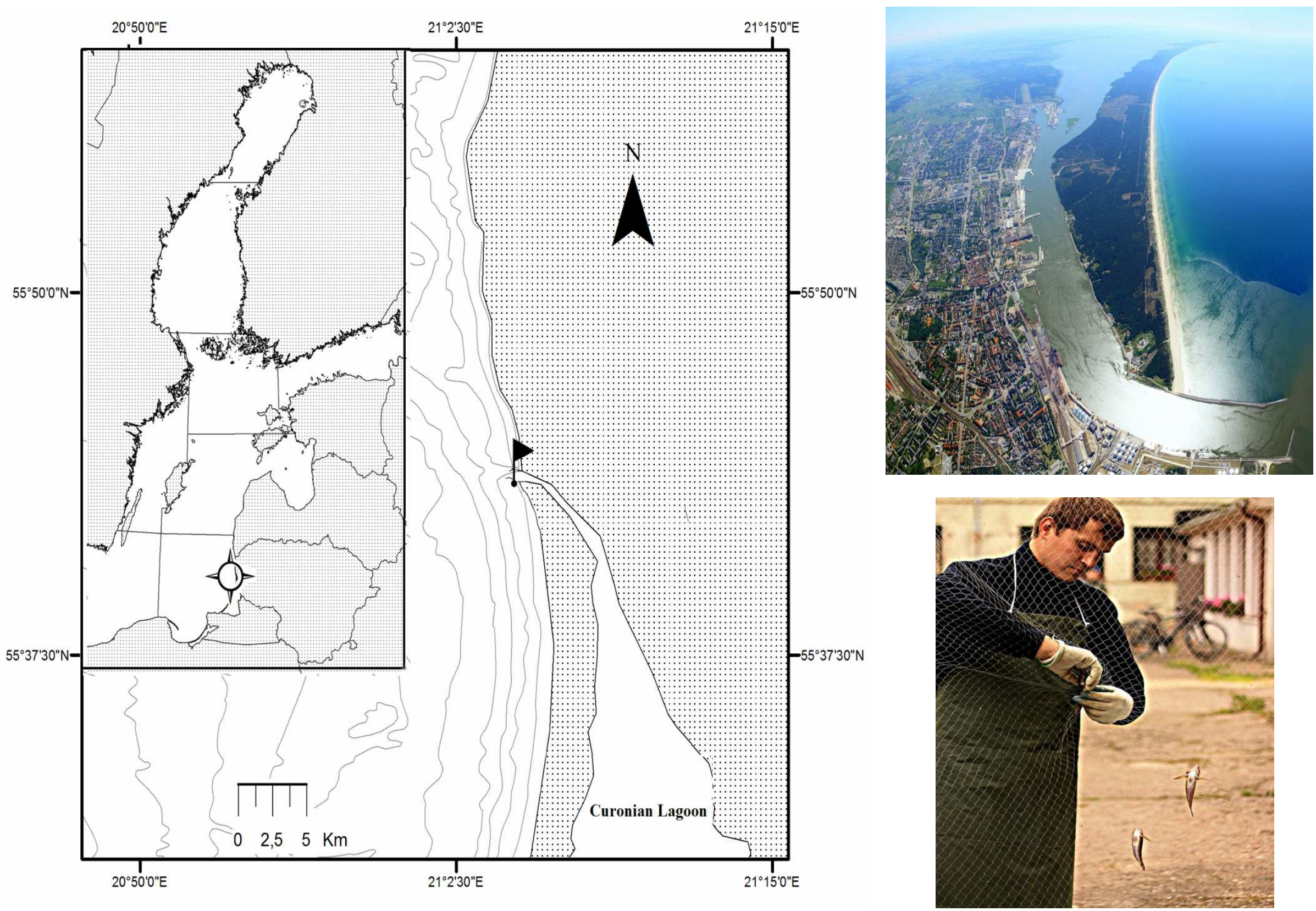


\section{Main prey items of round goby}

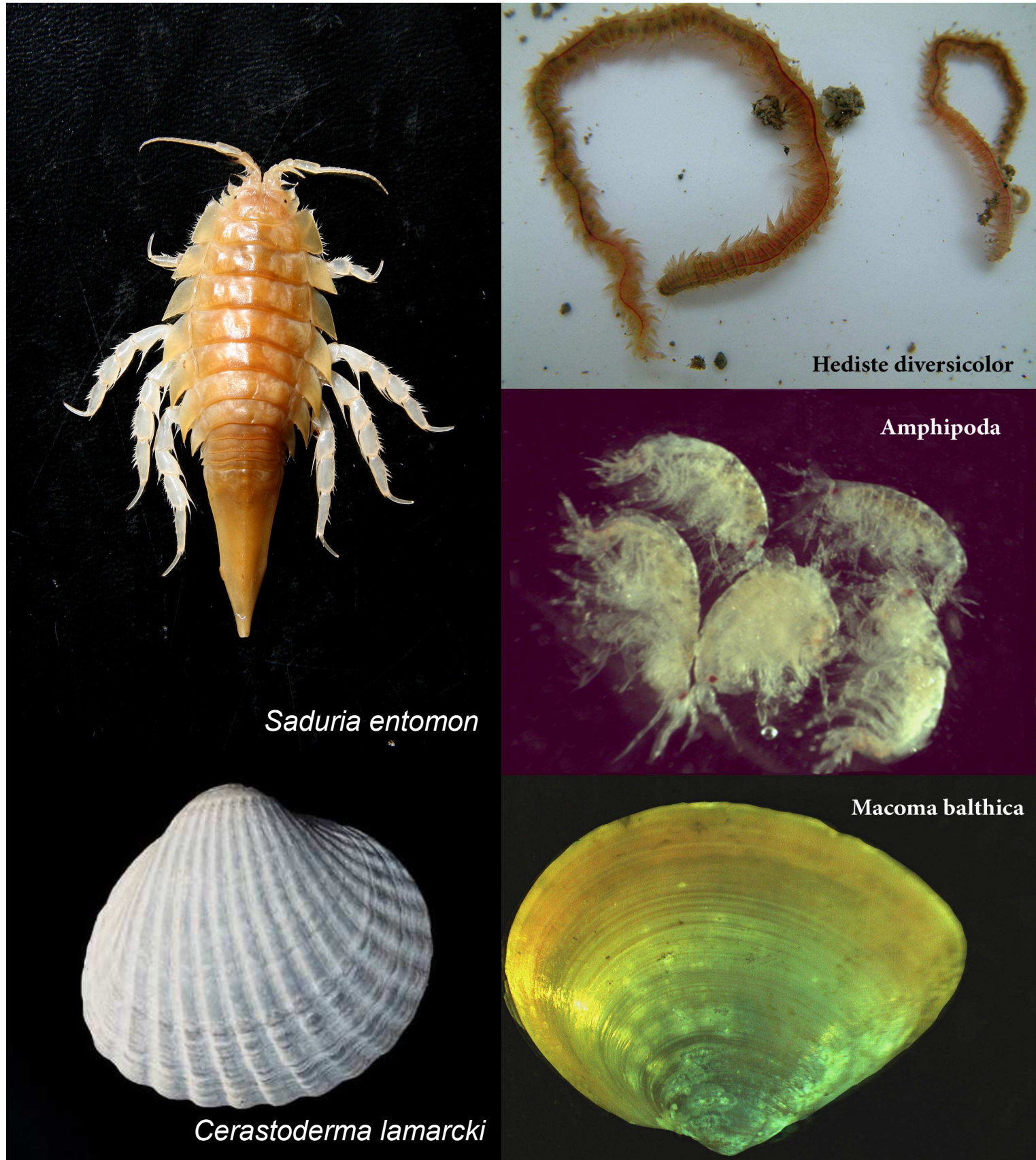

Pisces sp.

Balanus improvisus
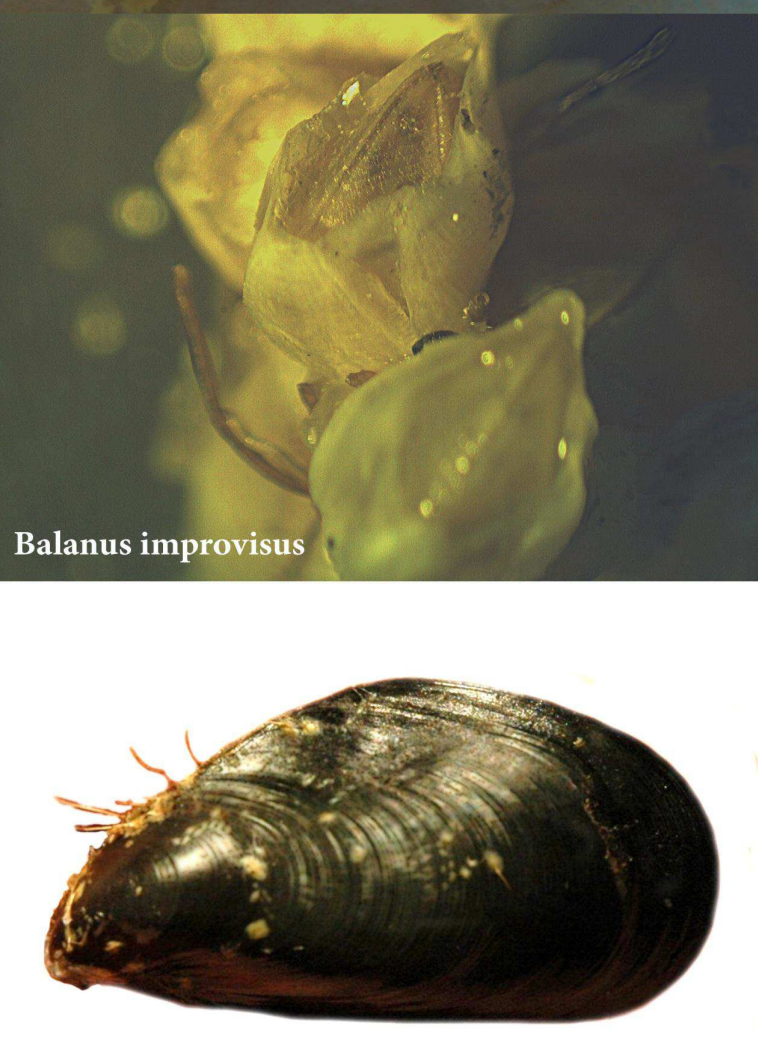

Mytilus trossulus 
Changes of feeding activity of differently sized female and male round gobies during May-October 2012.

Females

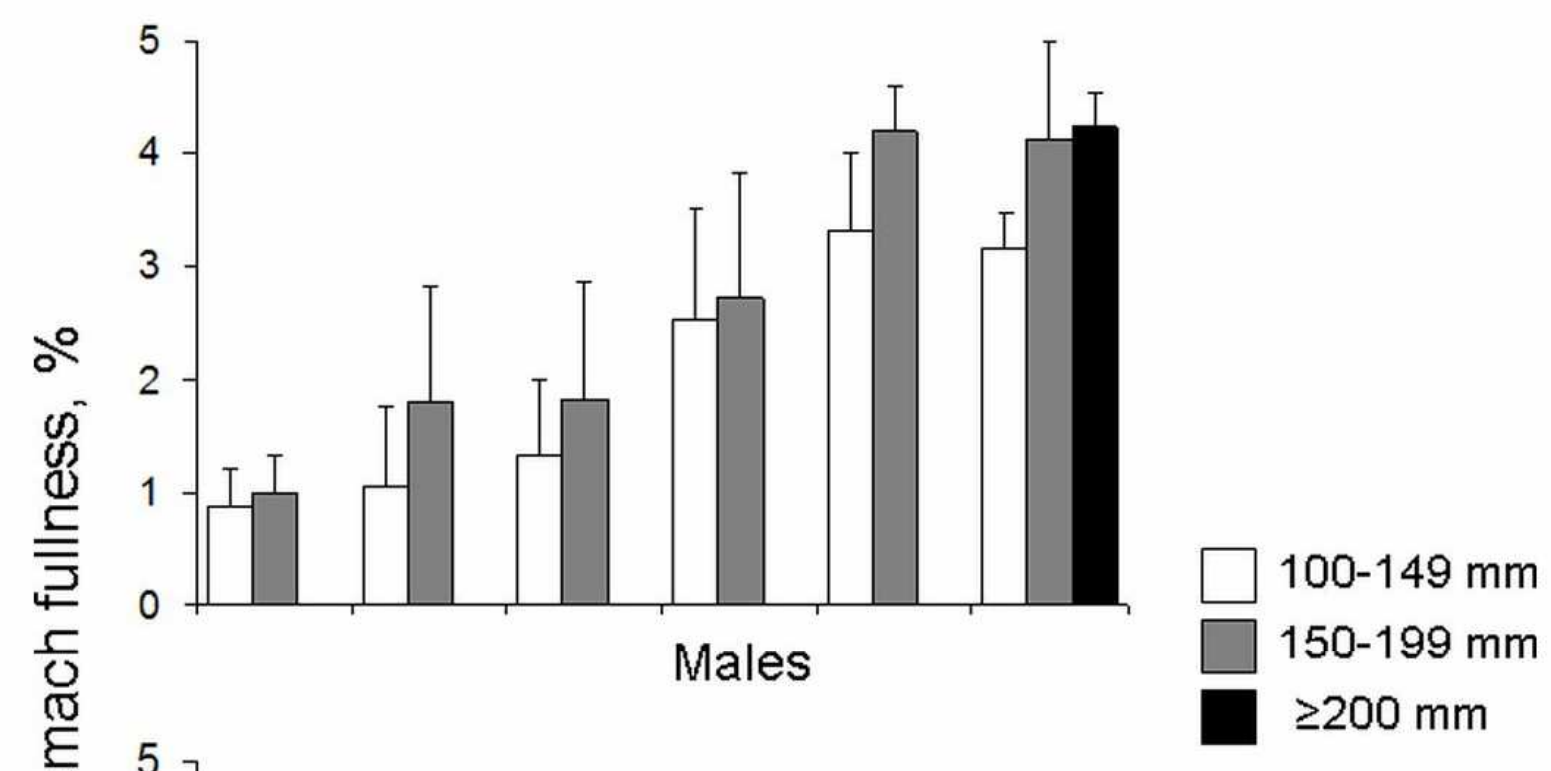


Ontogenetic and seasonal dietary changes of the round goby

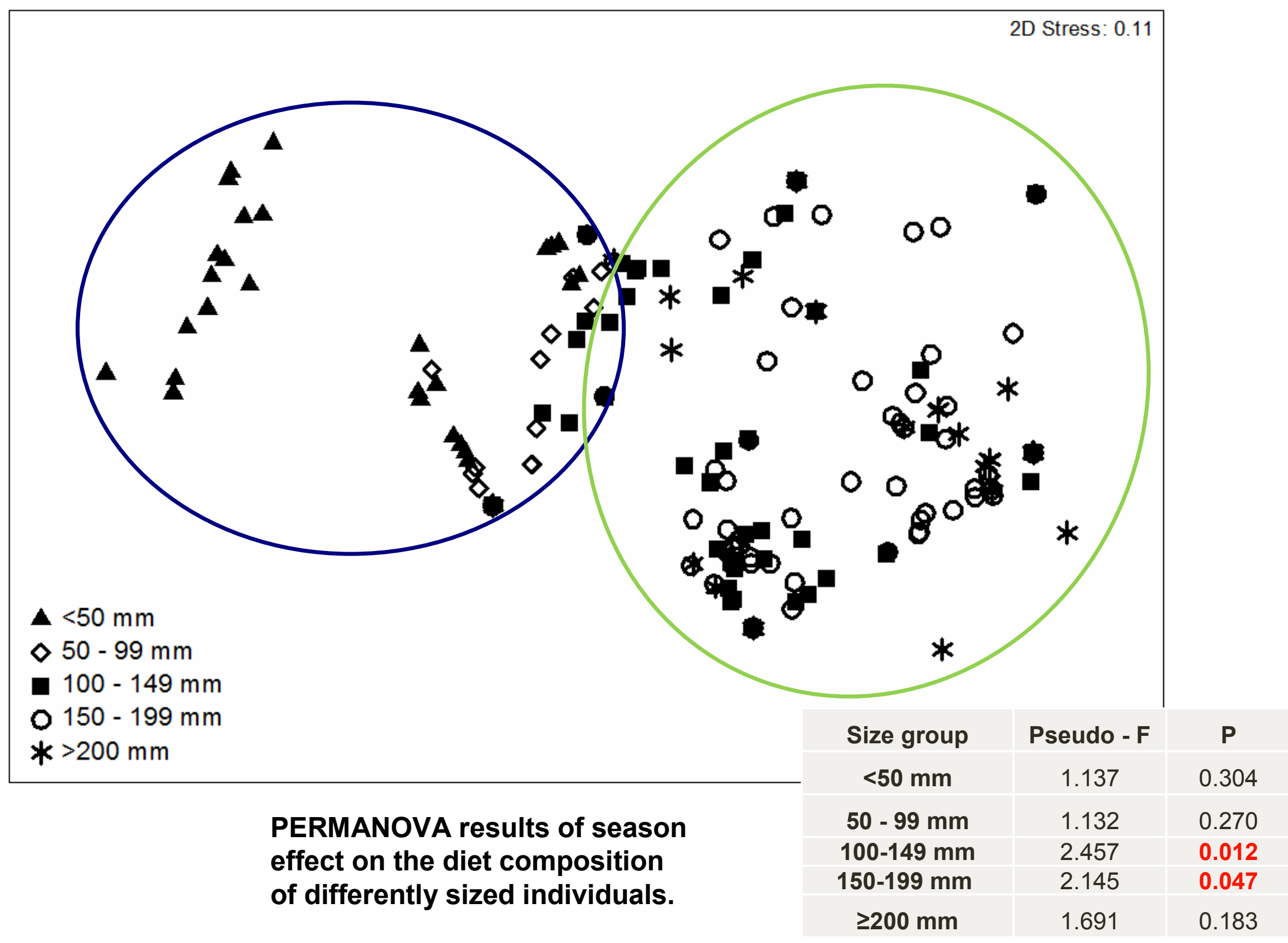


Seasonal dietary changes of the round goby. Spring

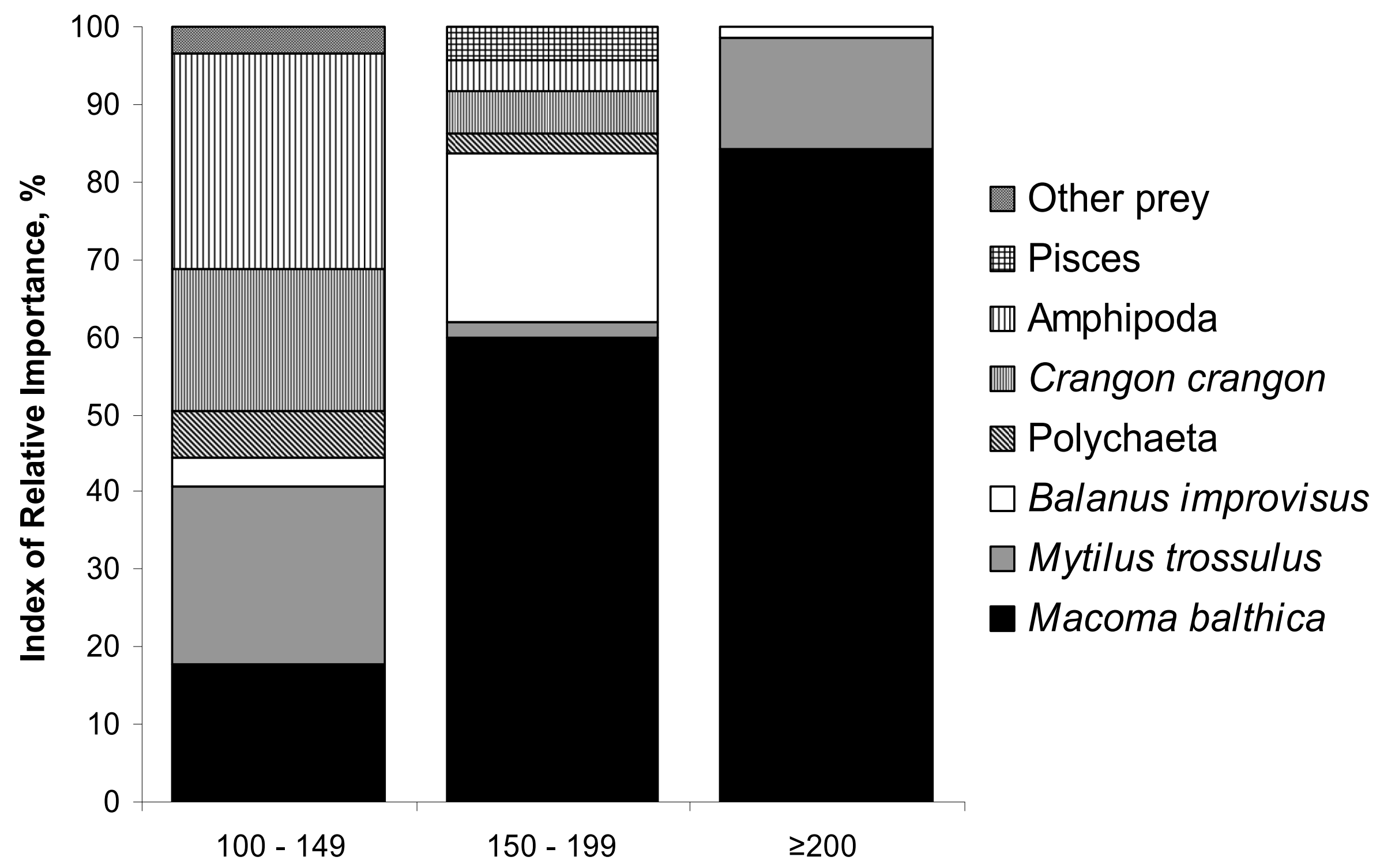

Size groups, mm 


\section{Summer}

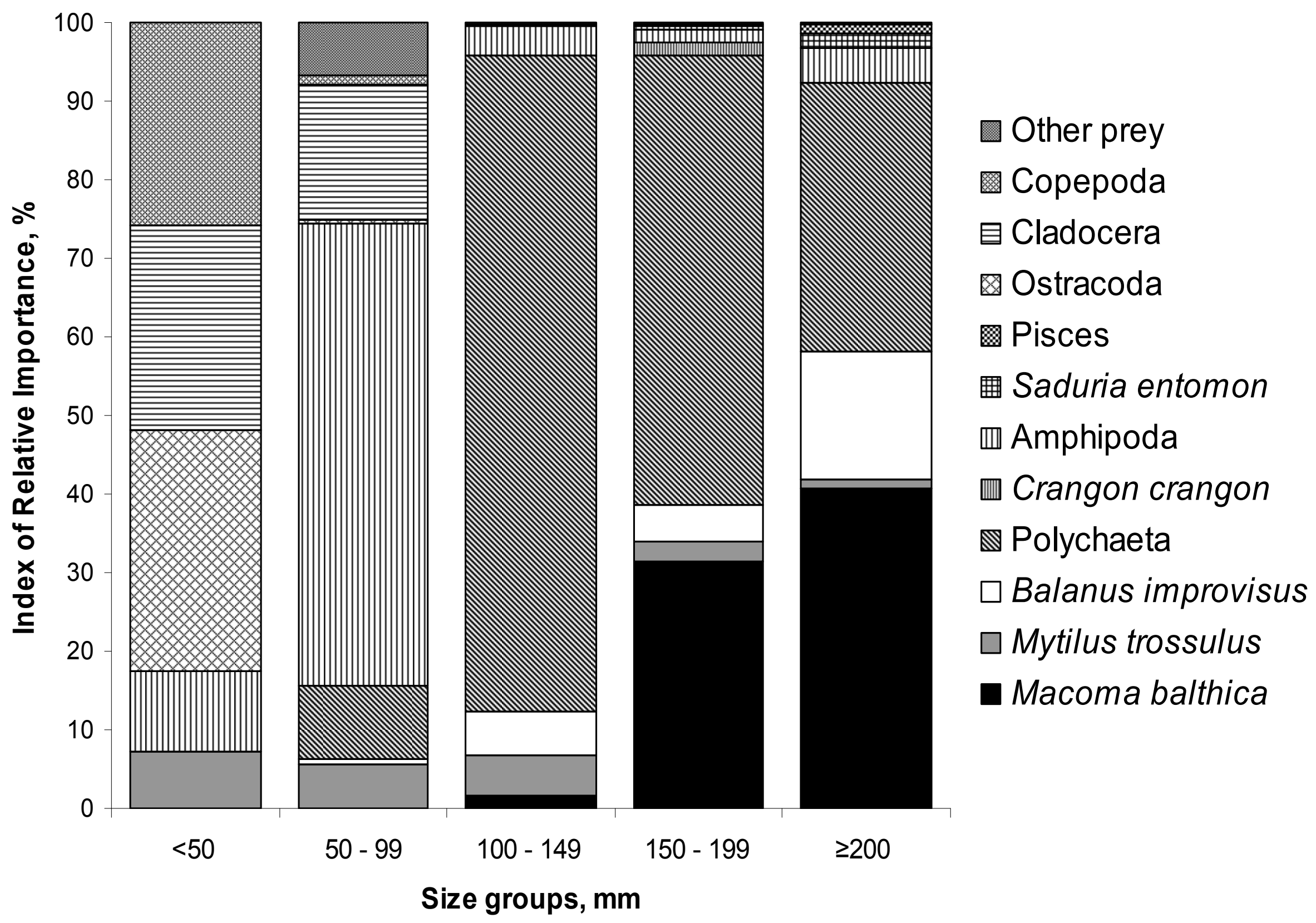




\section{Autumn}

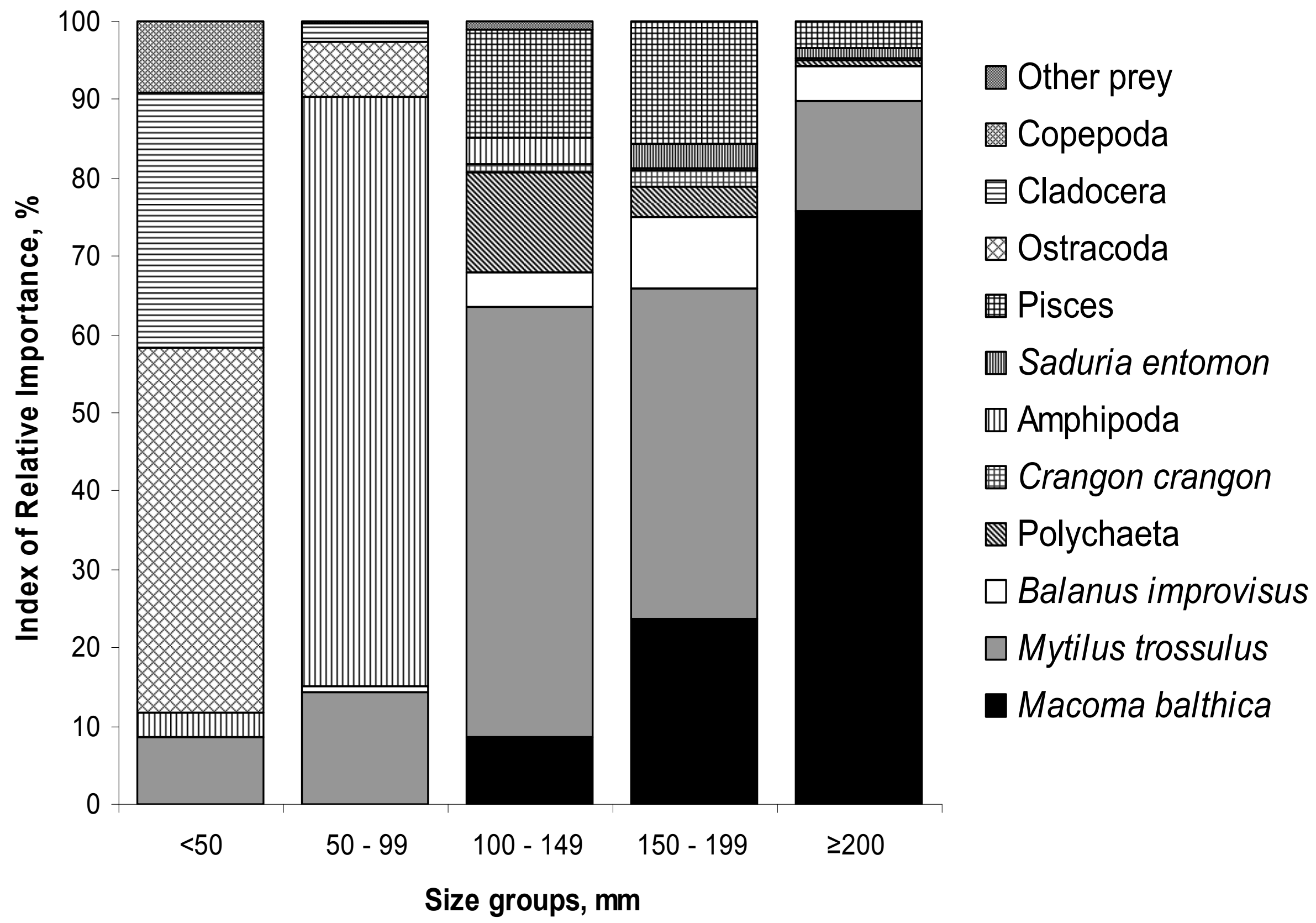




\section{Conclusions}

- Feeding activity of round goby varied depending on body size, sex and stage of the reproduction period;

- Ontogenetic dietary shift from zooplankton, meiobenthos and amphipods towards mollusks occured at the size of $100 \mathrm{~mm}$;

- Diet composition of round gobies $<100 \mathrm{~mm}$ and $\geq 200$ $\mathrm{mm}$ was relatively constant, while individuals of the intermediate 100-200 mm length had more variable ration, which changed depending on the season; 


\section{Thank you for your attention}

